\title{
Distribución del ingreso rural en Colombia y línea de pobreza: 2004-2014.
}

\section{Brayan Alexander Baron Ortegon}

\author{
babarono@unal.edu.co
}

\section{Resumen}

En este trabajo se responde a la siguiente pregunta ¿Por qué en el periodo: 2004-2014, se redujo la pobreza rural en Colombia, si la concentración del ingreso rural no disminuyo? Para responderla, se hace un análisis de las tasas de crecimiento de las series de crecimiento del ingreso rural, distribución del ingreso rural, pobreza rural, Gini del ingreso y población rural. Luego de responder la anterior pregunta, se hace una descripción del impacto de la disminución de la pobreza rural en el periodo estudiado, sobre algunas de las variables de calidad de vida de la población rural, para concluir que estos fueron débiles.

\begin{abstract}
In this paper, the next question is answered: Why in the study period 2004-2014, Colombian rural poverty decreased, even if rural income shares did not change? to do it, an analysis of growth rates of some economic series is done, such as: rural income growth, rural income shares, rural poverty, Gini coefficient of income and rural population. After, possible impacts of the decreasing rural poverty on some quality of life variables of Colombian rural population are described, concluding finally that they were scants.

\section{Palabras clave}

Desarrollo económico rural; Política pública rural, Pobreza rural; Colombia; Ingreso rural; Población rural.

\section{Keywords}

Rural development economics; rural public policy; rural poverty; Colombia; rural income; rural population.
\end{abstract}

Códigos JEL: D3, D31, D33, O1, O15. 


\section{Introducción}

En Colombia, como en la mayoría de países alrededor del mundo, desde la década de 1970 se ha visto una explosión en la desigualdad del ingreso, tanto urbana como rural. Lo cual ha tenido implicaciones en las mejoras potenciales y reales del nivel de vida de la población colombiana, asociadas a unos niveles potenciales y reales de ingreso en un momento dado (Hernández, 2015). Por lo tanto, la pregunta a la que nos enfrentamos es: ¿Por qué en el periodo: 2004-2014, se redujo la pobreza rural, si la concentración del ingreso rural no disminuyo? La elección del periodo ha tenido en cuenta dos factores: la disponibilidad de datos y la actualidad de la pregunta y consecuentemente su mayor relevancia.

Antes que nada, es importante decir que la CEPAL que es la principal fuente de datos en este trabajo, usa en sus bases de datos, las definiciones de los entes estatales de cada país encargados de la publicación de estadísticas, en el caso colombiano, el DANE ${ }^{1}$. La definición dada por el DANE (2016, p.1) de ruralidad y por lo tanto la aquí usada es:

“Área rural o resto municipal: se caracteriza por la disposición dispersa de viviendas y explotaciones agropecuarias existentes en ella. No cuenta con un trazado o nomenclatura de calles, carreteras, avenidas, y demás. Tampoco dispone, por lo general, de servicios públicos y otro tipo de facilidades propias de las áreas urbanas."

Vemos que esta definición es determinista y solo tiene en cuenta la concepción de espacio absoluto $^{2}$, además se hace una comparación respecto a lo urbano, como norma. Es importante tener en cuenta esto, dado que todos los datos aquí usados parten de esta definición, influyendo por lo tanto en el análisis aquí hecho.

Este trabajo se enfocará en la distribución del ingreso rural, la cual dada las particularidades de los diferentes territorios ${ }^{3}$ rurales colombianos, han presentado unas características

\footnotetext{
1 Vale la pena resaltar que, en el año 2006, el DANE llevo a cabo una reforma en su metodología y tratamiento de datos, lo que hace que muchas series producidas por la institución no tengan observaciones para los años: 2006 y 2007. En este trabajo, cuando las observaciones de los años 2006-2007 no estén disponibles, se usará para estos años el promedio simple entre las observaciones de los años: 2004, 2005, 2008 y 2009.

2 En este trabajo se usa la definición de Harvey (2006) de espacio absoluto, relativo y relacional.
} 
propias, pero también han tenido algunos elementos comunes. Estos últimos han sido principalmente:

1. Un largo conflicto armado, el cual ha desplazado a millones de personas y ha llevado al despojo y apropiación (legal y no legal) de millones de hectáreas de propiedad campesina y pequeños productores, por parte de grupos armados, latifundistas, empresas multinacionales, etc. (Fajardo, 2015).

2. La altísima concentración de la propiedad rural (Gini 0.87) (CNMH, 2013), que implica no solo ineficiencias económicas (Los campesinos y pequeños productores, en general, son más eficientes, competitivos y productivos), sino también consecuencias en otros aspectos sociales, pues a través de esta concentración, se da una jerarquía relacional de dominación, apaciguamiento y explotación a nivel territorial, social, político, económico y cultural. Este conjunto de relaciones es mantenido a través de la violencia (armada, cultural e institucional) (Ibáñez, 2011; Binswanger et al, 1995).

3. El Estado y su incapacidad de cumplir todos sus deberes constitucionales, en la mayoría del territorio nacional, especialmente las regiones más apartadas. Esta incapacidad histórica, ha llevado a que, en estas regiones, esos vacíos de poder e institucionales sean llenados con poderes regionales y locales, los cuales solo siguen sus propios intereses rentistas-especulativos, políticos, sociales, etc. En detrimento del bienestar, propiedad e inclusive la vida de las comunidades e individuos (generalmente pequeños agricultores familiares y campesinos) que viven en estos lugares. Esta debilidad, ha sido aprovechada muchas veces por estos poderes locales, para usar y capturar la poca presencia estatal en estos niveles y usarla para lograr sus distintos fines (Fajardo, 2013). 


\section{Distribución del ingreso rural en Colombia y pobreza rural: 2004-2014.}

Para entender la distribución del ingreso rural y la pobreza rural, en el periodo: 2004-2014, se debe entender primero, como han variado el crecimiento del ingreso per cápita, la distribución del ingreso rural y la línea de pobreza rural.

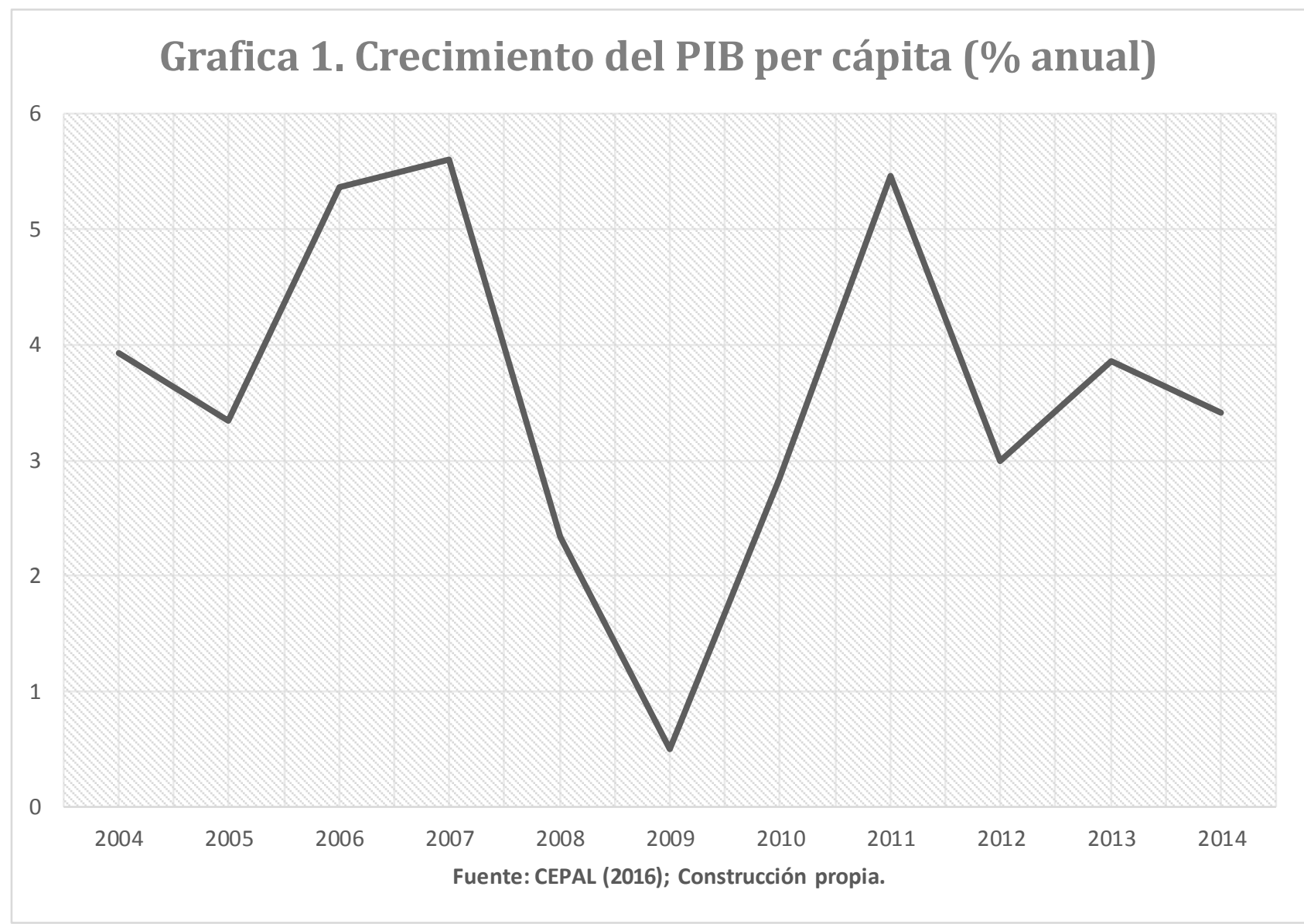

Durante el periodo, la tasa de crecimiento del ingreso per cápita colombiano fue del 3.6\% en promedio (Grafica1.), el cual estuvo por encima del promedio latinoamericano (2.5\%) (CEPAL, 2016). 
Durante el periodo de estudio la contribución promedio de Agricultura, ganadería, caza, silvicultura y pesca a la tasa de crecimiento del producto interno bruto (PIB), fue de tan solo $0.15 \%$, incluso mostrando una tendencia decreciente, cayendo desde el $0.2 \%$ en 2004 al $0.15 \%$ en 2014, siendo algunos años negativa (CEPAL, 2016). La Participación en el producto interno bruto (PIB) del conjunto de estos sub-sectores económicos fue en promedio 6.8\%, cayendo desde el 7.8\% en 2004 al 6.2\% en 2014 (CEPAL, 2016). Es notable que estando tan ligada a la propiedad territorial rural y por lo tanto a un conflicto tan agudo y cruento como el colombiano, la contribución al crecimiento y participación en el ingreso promedio de Agricultura, ganadería, caza, silvicultura y pesca sean tan bajas en comparación a sectores como el industrial (0.4\%) (CEPAL, 2016). Esto podría interpretarse como un reflejo de la ineficiencia económica extrema en el uso de estos recursos, usos que están ligados directamente a las distintas configuraciones sociales, económicas y políticas en estas áreas, especialmente en la propiedad (concentración de la tierra) y formas de tenencia de la tierra (Fajardo, 2003). Usos que no necesariamente tienen en mente, la

\section{Grafica 2. Distribución porcentual de la población en áreas urbana y rural (Proyecciones*).}

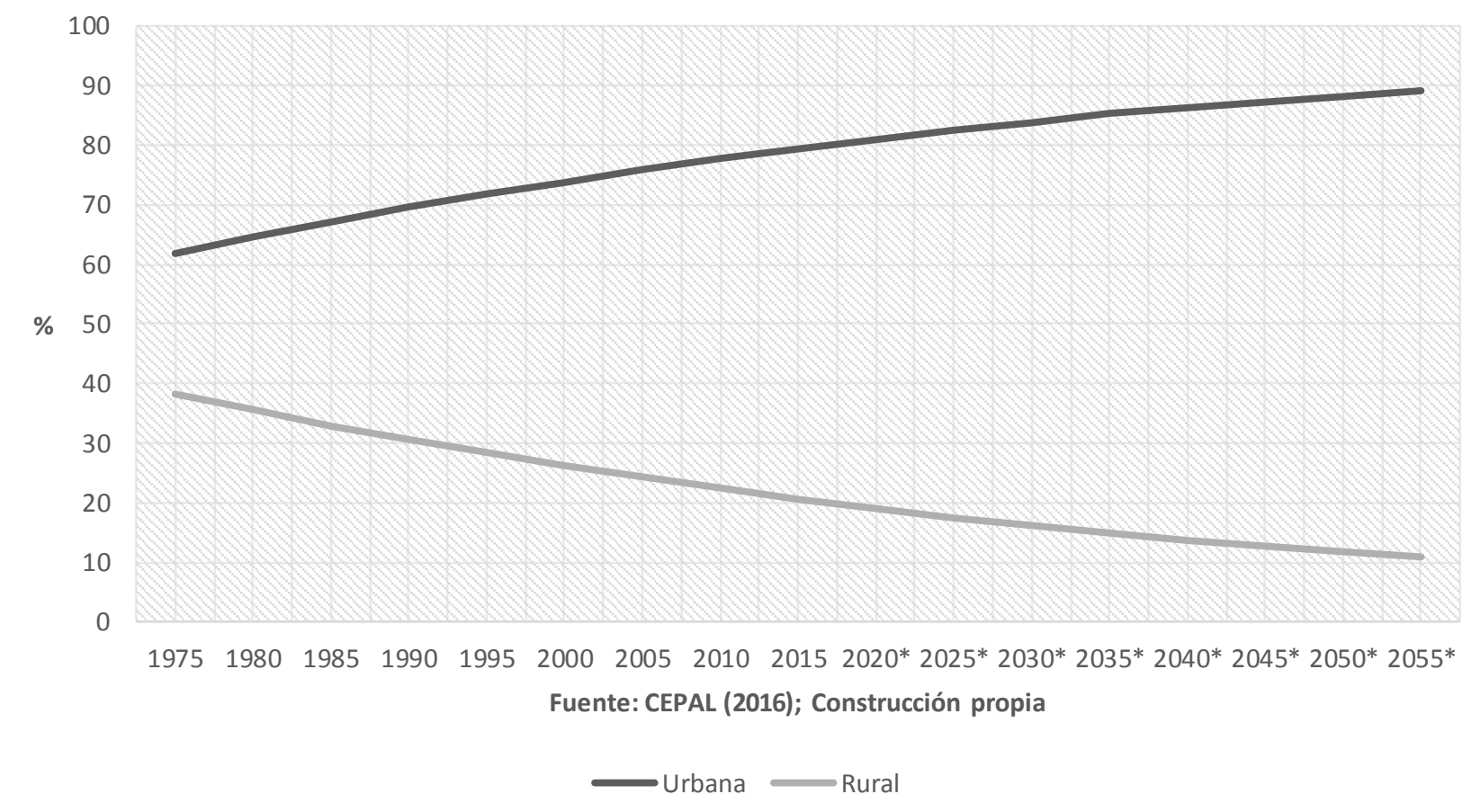


maximización de la eficiencia y competitividad productiva, sino que pueden responder a otras lógicas de acumulación, de poder político y económico.

En la Grafica 2. Se puede observar una tendencia decreciente de la población rural, que paso de ser casi el $40 \%$ de la total a mediados de la década de los setenta del siglo XX a solamente el $24 \%$ en el 2004 y $20 \%$ en el 2014, se espera que a mediados del siglo XXI sea de tan solo un 10\% (CEPAL, 2016).

\section{Grafica 3. Índice de concentración de Gini del ingreso en áreas rurales.}

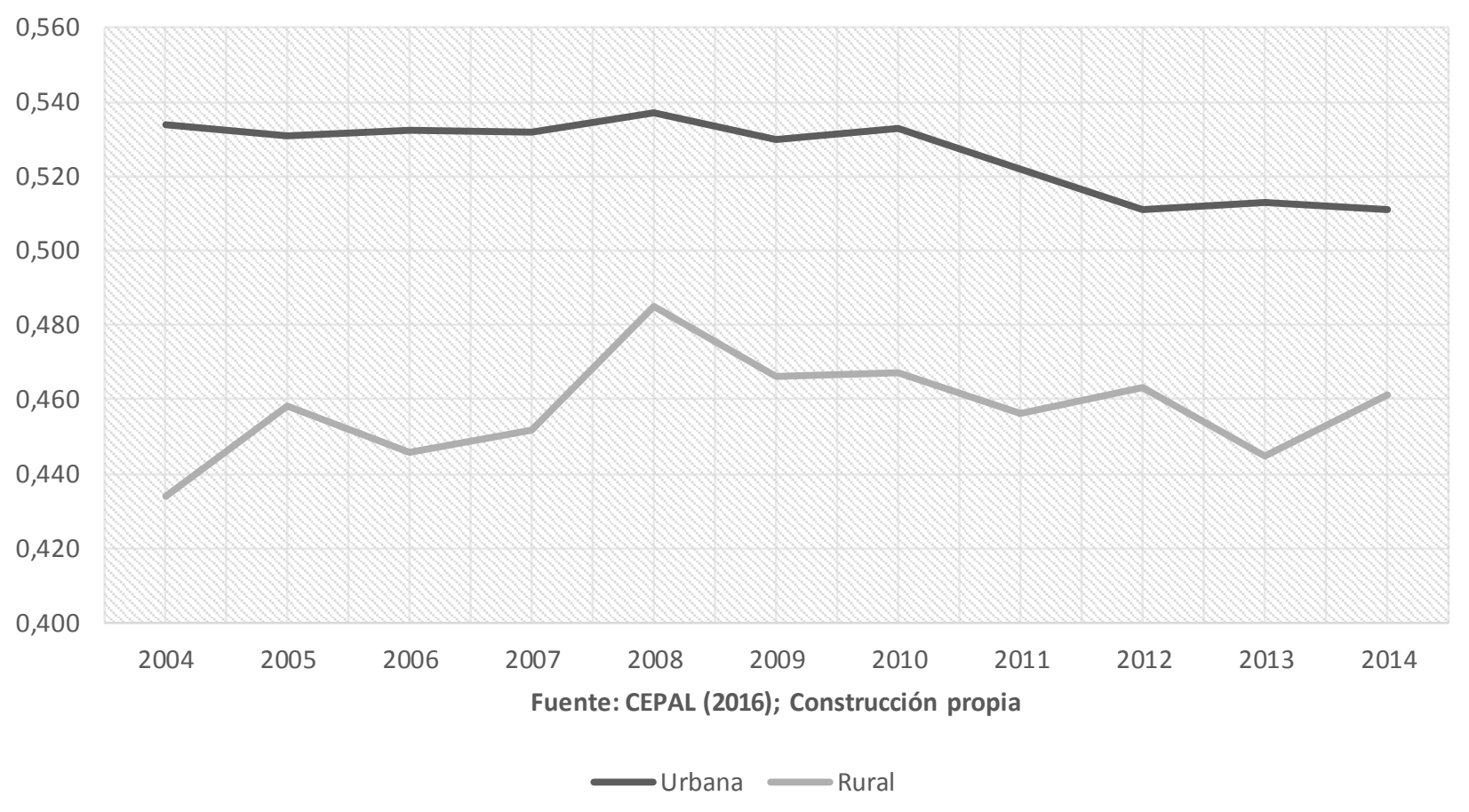

La disminución del porcentaje de la población rural respecto al total, no es un fenómeno exclusivo de Colombia, sino es parte de una tendencia global de movilidad del trabajo, resultado de la perdida de participación de la agricultura en el PIB mundial y del modelo de desarrollo imperante (Correa, 2012), un fuerte proceso de urbanización y en el caso colombiano, es muy probable que esta disminución se vea acelerada por los procesos sistemáticos de desplazamiento forzado, despojo de la propiedad de campesinos y pequeños 
agricultores, con el fin de concentrar la propiedad de la tierra. Este cambio en la participación poblacional es uno de los elementos más relevantes para dilucidar la distribución del ingreso, pues no solo es importante entender como ha crecido el ingreso, sino también dentro de cuantos se reparte ${ }^{4}$.

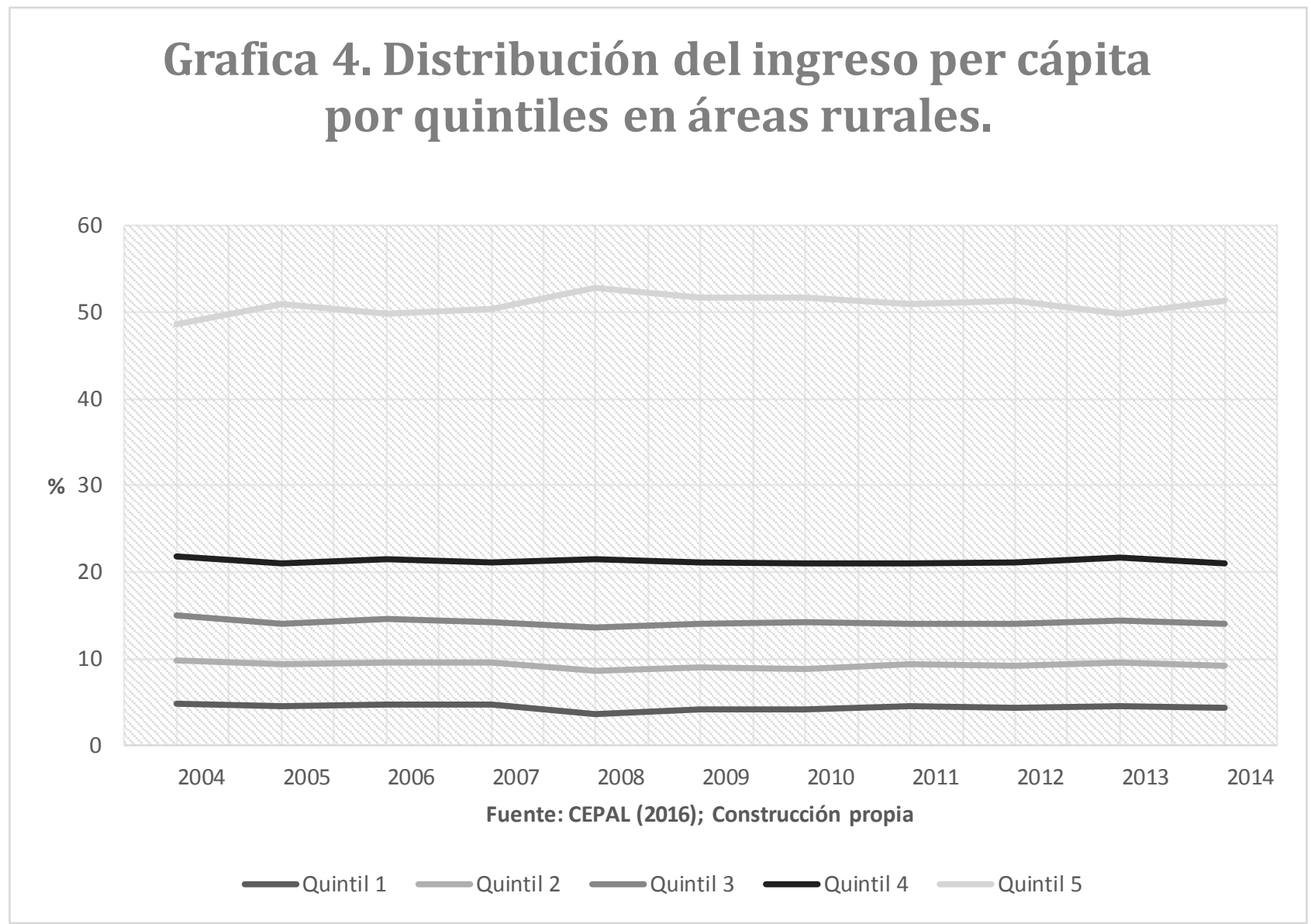

\footnotetext{
${ }^{4}$ En este punto, el economista inglés David Ricardo se sonrojaría, pues el análisis aquí hecho es puramente determinista, tiene tintes de su propia teoría de la distribución, dados unos recursos, un crecimiento poblacional promedio, unos inversionistas, unos trabajadores libres, unos derechos de propiedad de unos propietarios rurales, a través de unas actividades productivas el mecanismo económico alcanza una distribución del ingreso (Ricardo, 2003). No se ha tenido en cuenta, por lo tanto, el mecanismo político y el social, que también juegan un papel en la distribución.
} 
En la Grafica 3. Se puede observar una leve tendencia creciente del Gini del ingreso rural, la cual fue en promedio del 0.46, por debajo del promedio latinoamericano (0.48) (CEPAL, 2016). Al comparar el Gini rural con el Gini del ingreso urbano, este último si disminuyo, a pesar de que el porcentaje de la población urbano creció (CEPAL, 2016). Al mirar la distribución del ingreso por quintiles (Grafica 4.), únicamente se puede ver cinco curvas casi totalmente planas, en otras palabras, la distribución del ingreso rural permaneció virtualmente inalterada durante los diez años de análisis, por lo que podemos decir que (ceteris paribus) si los índices de pobreza cambiaron, esto no se debió a una redistribución más equitativa del ingreso.

\section{GRAFICA 5. LÍNEAS DE INDIGENCIA Y POBREZA-PESOS CONSTANTES (2010).}

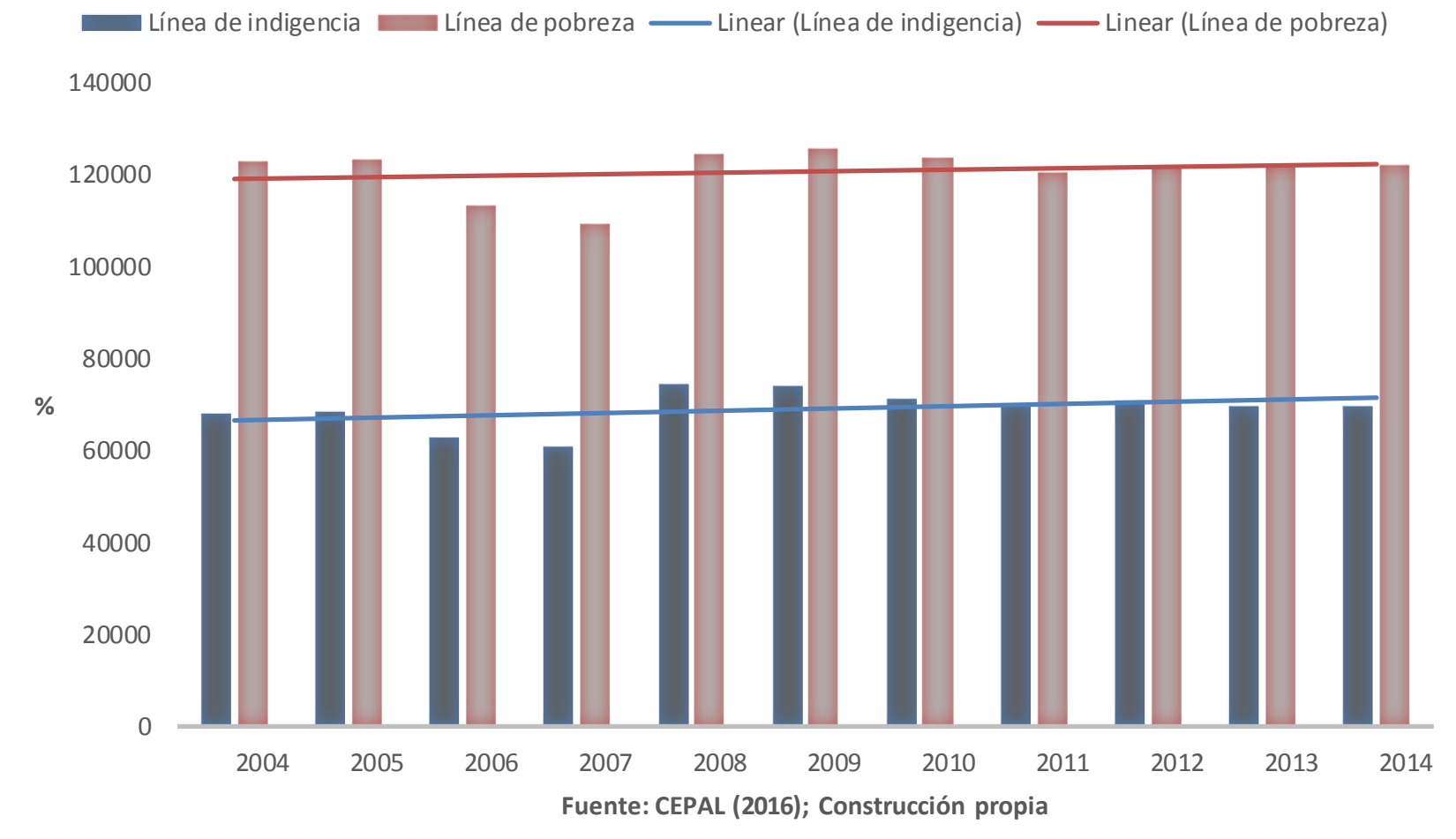

En la Gráfica 5 es posible ver que la línea de pobreza, la cual se establece para cada año en términos de moneda local, no cambio prácticamente nada durante el periodo 2004-2014, siendo en promedio igual a $\$ 120.000$ pesos constantes del 2010. Esta es una de las posibles 
razones para que la pobreza haya disminuido, a pesar de que la distribución del ingreso no haya mejorado en nada. Al tener una línea de pobreza con un punto de corte bajo (respecto al salario mínimo promedio durante el periodo: $\$ 507.140^{5}$ (BCRC, 2016)) y virtualmente constante, al mismo tiempo que una redistribución del ingreso total y laboral prácticamente nulas, un crecimiento del ingreso rural positivo y una reducción en el porcentaje de población rural respecto al total, hacen inevitable que, en términos de la línea de pobreza, la pobreza haya caído (Grafico 6.). En otras palabras, la tasa de crecimiento del ingreso per cápita (3.6\%) seria mayor que la suma de la tasa de crecimiento del Gini del ingreso rural $(0.67 \%)$, de la población rural $(0.0042 \%)$ y de la línea de pobreza rural $(0.06 \%)$.

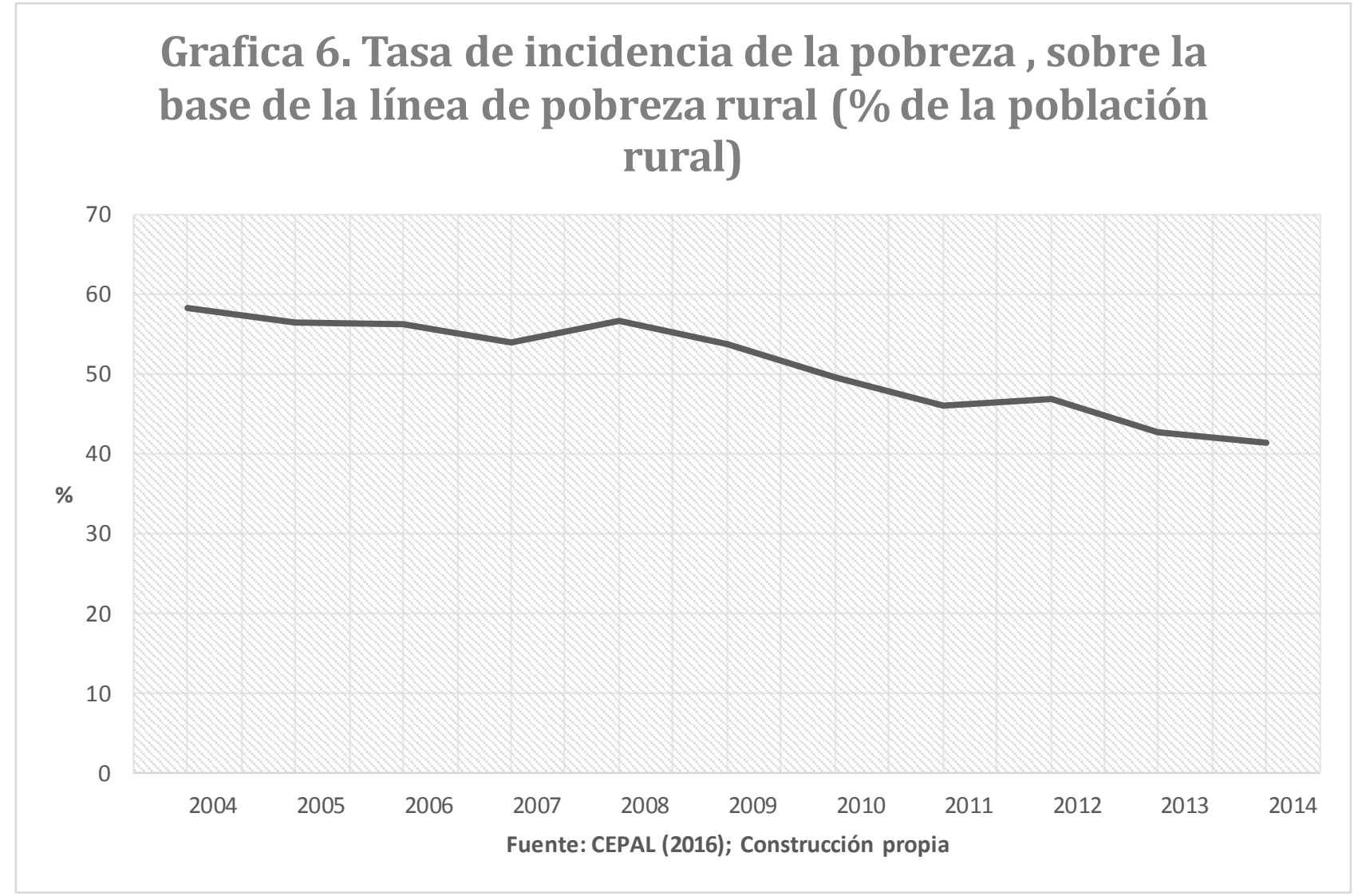

\footnotetext{
${ }^{5}$ Para esta serie se usó el Deflactor del PIB, año base 2010 (CEPAL, 2016). Salario mínimo promedio a precios constantes 2010 (Usando el Deflactor implícito del PIB, (CEPAL, 2016)). La serie de salario mínimo se tomó del Banco Central de la Republica de Colombia (BCRC) (2016). http://www.banrep.gov.co/es/indice-salarios
} 
Para que la anterior tesis sea válida, se supone que el crecimiento del ingreso rural es proporcional al crecimiento del ingreso per cápita nacional, debido a que no se dispone de la serie de ingreso per cápita rural. También debe tenerse en cuenta de que esto solo sería válido si se supone que el crecimiento de este ingreso es mayor al decrecimiento de la participación de los sectores económicos rurales en el PIB. Por lo anterior, se construirá la serie de ingreso per cápita rural, tomando el PIB total a precios constantes (2005), la participación de Agricultura, ganadería, caza, silvicultura y pesca en el PIB y la población rural total. Se incluyen estas dos últimas variables, en orden de corregir la disminución de la población y la perdida de participación en el PIB de los sectores rurales:

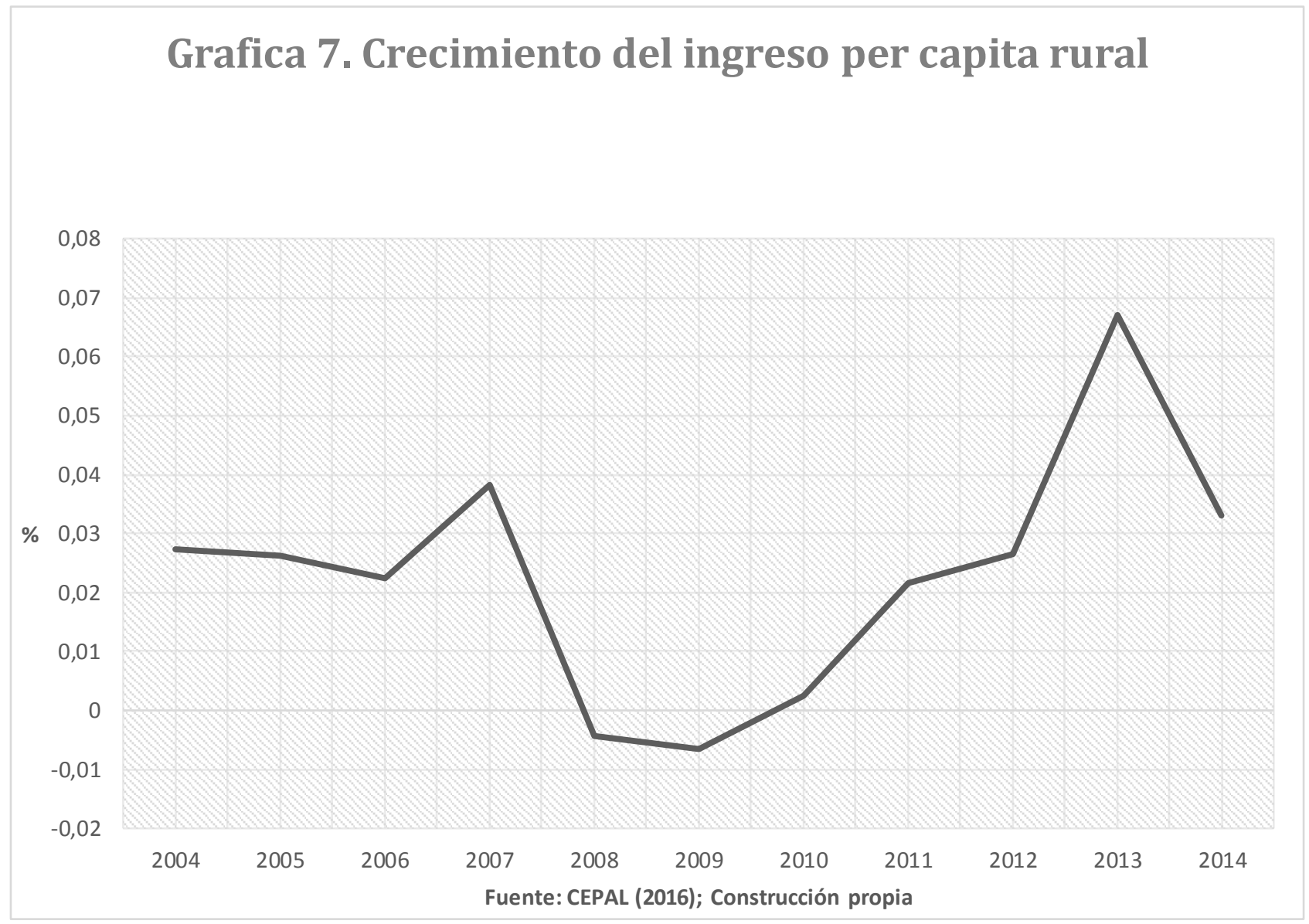

En la Gráfica 7. Se puede ver que como se podía esperar, el comportamiento del ingreso per cápita en las áreas rurales es similar al nacional, sin embargo, el promedio del ingreso per 
cápita rural es mucho menor (2.31\%) comparado con el nacional (3.6\%). Además, como se había dicho antes, el porcentaje de población rural con respecto al total cayo, siendo la tasa de crecimiento de la población rural muy cercana a cero $(0.0042 \%)$ (Grafica 8). En resumen, a la luz de estos datos, la tesis anteriormente dicha sobre las razones de la caída de la pobreza (Graficas 8 y 9.), sigue siendo válida, pues ni siquiera la suma de las tasas de crecimiento promedio del Gini, población y línea de la pobreza, superan la tasa de crecimiento promedio del ingreso per cápita rural, teniéndose al final que la tasa de crecimiento promedio de la pobreza rural promedio fue negativa $(-3.3 \%)$ :

$$
2.31 \%>(0.67 \%+0.0042 \%+0.06 \%)>-3.3 \%
$$

Por lo tanto, al ser mayor la tasa de crecimiento promedio del ingreso rural per cápita, que el crecimiento promedio de la población y el crecimiento promedio de la línea de pobreza, en un contexto donde la distribución del ingreso promedio cambia muy poco en comparación, hace que la pobreza monetaria (en precios constantes 2010) y por lo tanto la indigencia (pobreza extrema) se reduzcan en términos porcentuales (Grafica 8.).

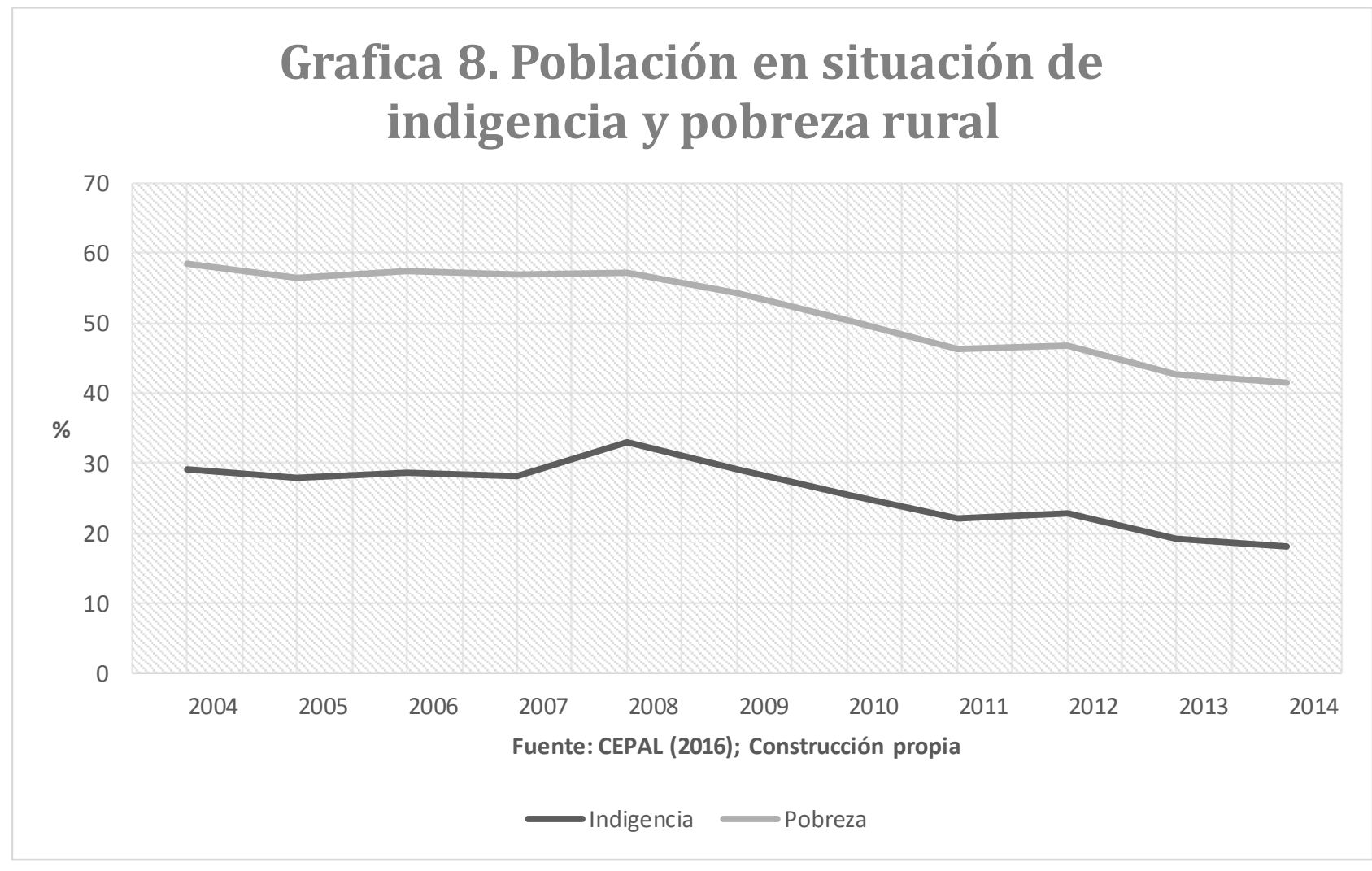


En la Gráfica 9. Se puede ver que, en términos de incidencia de la pobreza, respecto a la línea de la pobreza rural, el porcentaje de personas con un ingreso per cápita menor o igual a la línea de la pobreza, paso del 44\% en 2004 al 24\% en 2014.

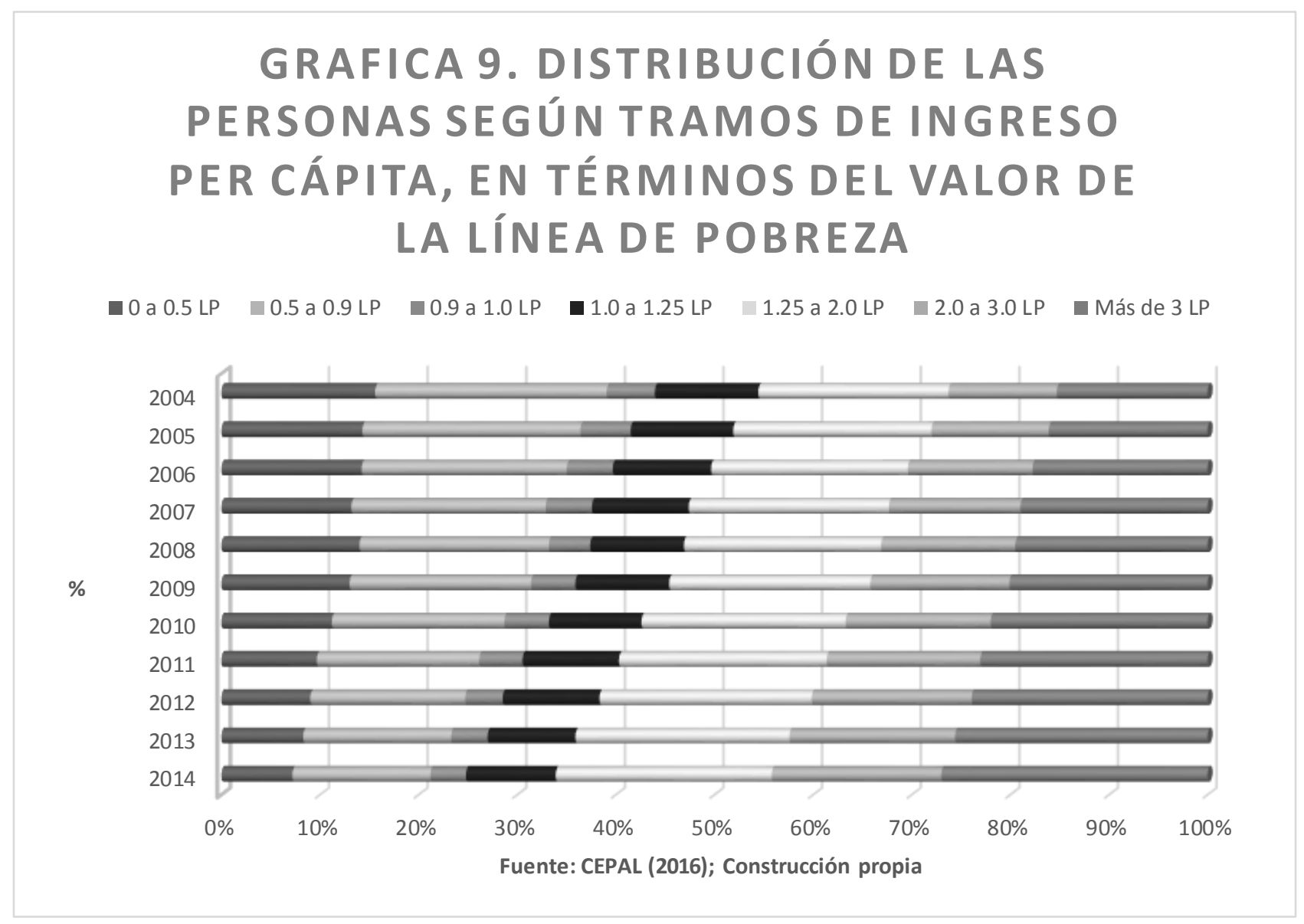

En línea con lo anterior, la alta tasa de inequidad en la distribución de los ingresos laborales, que según Joumard y Londoño (2013) es una de las causas principales de pobreza. Esta distribución del ingreso laboral rural (Grafica 10.) permaneció al igual que la de ingresos totales virtualmente sin cambio, no obstante, los ingresos medios de la 
población ocupada crecieron $(2.18 \%)$, como los de los trabajadores por cuenta propia y familiares (no remunerados) de la agricultura, cuya tasa de crecimiento de los ingresos promedio fue del $2.63 \%$.

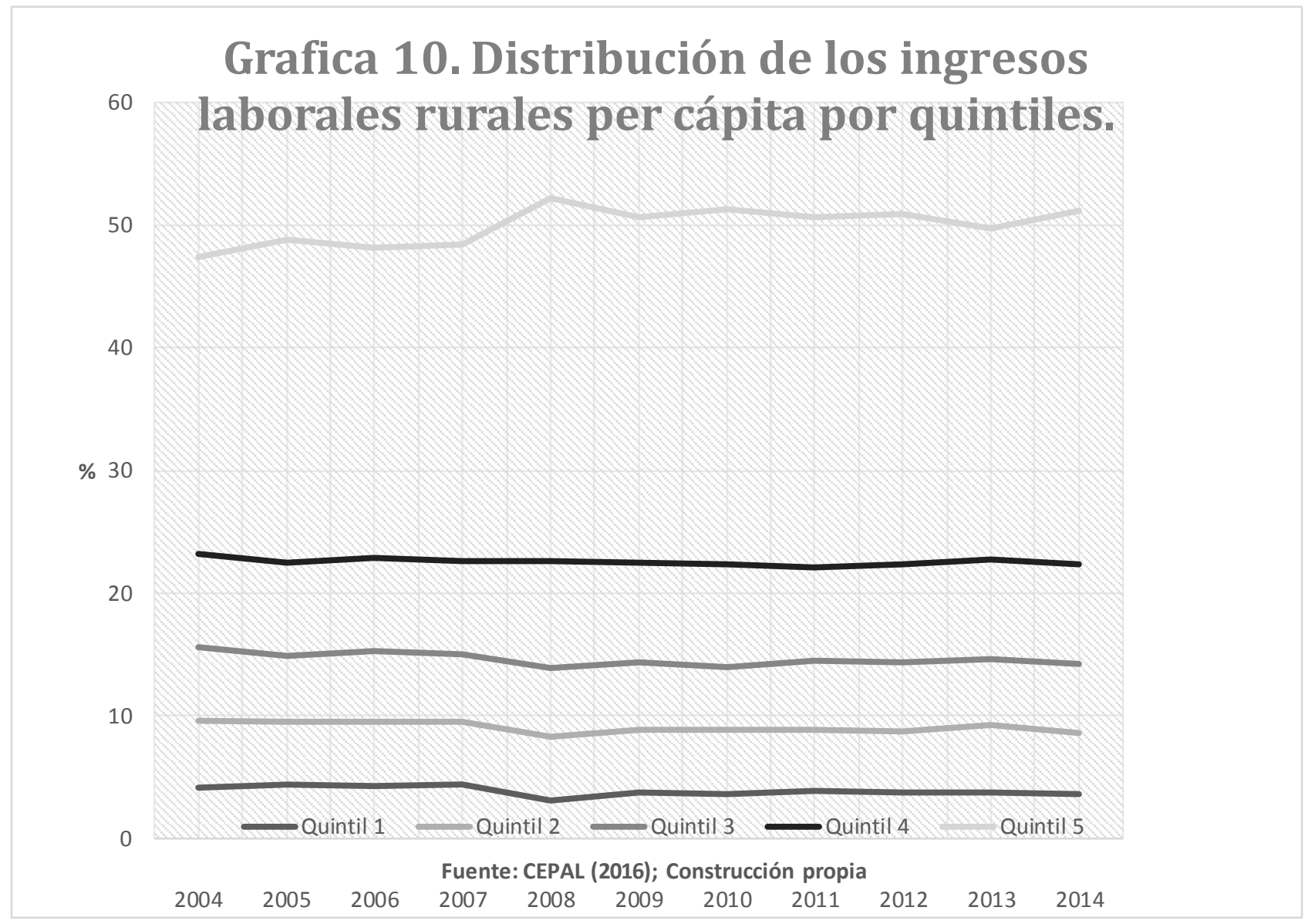

A pesar de la disminución de la pobreza e indigencia (esta última, en el periodo de estudio afecto a uno de cada cuatro habitantes rurales, en promedio), la población en áreas rurales aún sufre de muchas carencias, no solo materiales, sino también de invisibilización política, violencia armada, institucional, infraestructura, educación. Un grupo es especialmente vulnerable, las mujeres.

Es importante saber que, en Colombia, durante el periodo de estudio, cerca del $20 \%$ de los, los ingresos en los hogares rurales provinieron de mujeres (CEPAL, 2016). Además, 
alrededor del 50\% de las mujeres rurales, se dedicaba exclusivamente a las labores del hogar (quehaceres domésticos). También, el $37 \%$ de las mujeres (mayores a 15 años) de los dos primeros quintiles del ingreso per cápita participaron en el mercado de trabajo. Por parte de los hombres el 82\% participaron laboralmente (CEPAL, 2016). En lo anterior, es posible ver la gran importancia de las mujeres no solo en el hogar, sino también como fuente de ingresos y sostén de la familia en el ámbito rural. Esto también es importante, si tenemos en cuenta que las diferencias de género han sido una de las causas de desigualdad del ingreso, acceso al trabajo, etc. de las mujeres. Con respecto a los hombres, un $15 \%$ más de la población femenina estuvo bajo la línea de pobreza y un 23\% más estuvo bajo la línea de indigencia (CEPAL, 2016), poniéndolas en una situación de mayor vulnerabilidad económica, social, sexual y de violencia doméstica, etc.

La proporción del ingreso medio de las mujeres respecto a los hombres, durante el periodo (2004-2014) fue mucho mayor a nivel urbano que (77\%) que a nivel rural (66 \%) (CEPAL, 2016), lo que evidencia una vez más la situación de vulnerabilidad y dependencia económica de las mujeres en las áreas rurales.

Con respecto a la asistencia escolar de la población entre 7 y 24 años, en el 2004 el 58.5\% recibió educación y en el 2014, este porcentaje alcanzo del $65 \%$ de la población, evidenciándose un crecimiento promedio del $1.17 \%$ en la asistencia escolar (CEPAL, 2016).

Durante el periodo (2008-2014), el 26.8\% de los hogares rurales no disponía del servicio básico de agua, el $13 \%$ no disponía de electricidad y el $24 \%$ de alcantarillado (CEPAL, 2016). Durante el periodo de estudio, el tipo de hogares según la condición de tenencia de la vivienda (Grafica 11.) no presento grandes cambios, esto puede estar relacionado con la también estabilidad en la distribución del ingreso. 


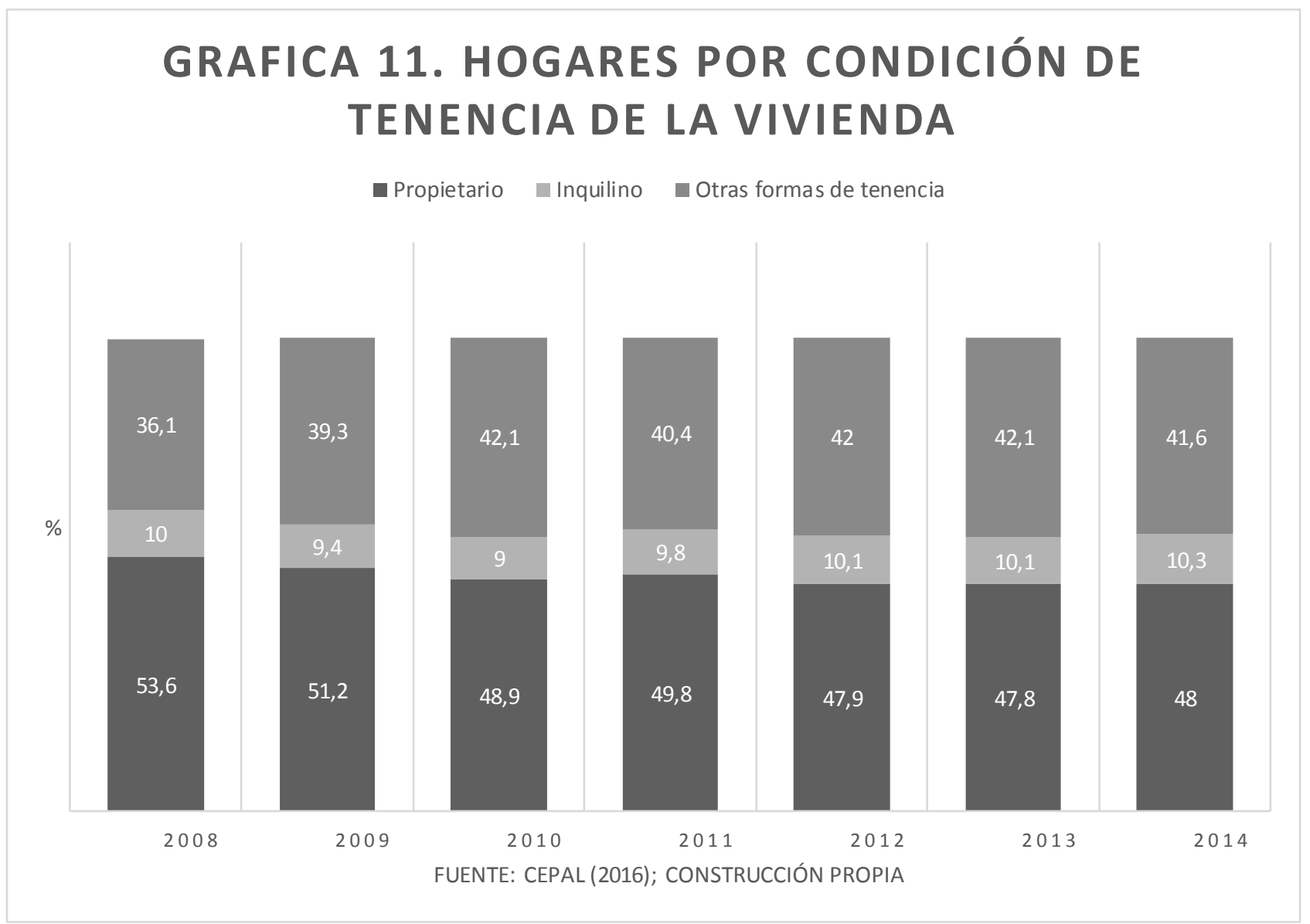

\section{Conclusiones}

En este trabajo se supone que Agricultura, ganadería, caza, silvicultura y pesca son sectores representativos de la estructura productiva en las áreas rurales en Colombia, durante el periodo de estudio. Vale la pena notar, que no se hacen supuestos adicionales sobre el tipo de producción usada $\mathrm{y}$, por lo tanto, tampoco sobre la propiedad rural (latifundista, producción a pequeña escala, etc.), simplemente se asume su ruralidad. Estos supuestos son de tipo deterministas y son inherentes a la definición de ruralidad aquí usada, por lo tanto, 
se debe tener precaución con el alcance de las conclusiones hechas, pues bien pueden no reflejar la situación de la distribución del ingreso de ciertas comunidades, campesinos, pequeños agricultores, etc. cuyas características podrían no estar recogidas necesariamente en la definición, invalidando la inducción de los resultados aquí presentados.

Para concluir, es importante resaltar, que a pesar de la disminución de la pobreza, según el criterio de línea de pobreza, durante el periodo de estudio alrededor el 33\% de la población en áreas consideradas rurales, tuvieron un ingreso inferior al 70\% de la mediana del ingreso rural, además la distribución del ingreso en Colombia es percibida por la población, como altamente inequitativa, en el 2015, el $85 \%$ de los encuestados a nivel nacional, declararon la distribución del ingreso como "injusta" (CEPAL, 2016). Esta desigualdad del ingreso rural tiene impactos negativos en el bienestar y calidad de vida de la población, por lo tanto, debería tenerse en cuenta en la formulación y ejecución de políticas públicas (Hernández, 2015: Fajardo, 2003).

\section{Referencias}

Binswanger, H. P., Deininger, K., \& Feder, G. (1995). Power, distortions, revolt and reform in agricultural land relations. Handbook of development economics, 3, 26592772.

Centro Nacional de Memoria Histórica. (2013). La política de reforma agraria y tierras en Colombia. $1^{\circ}$ Edición. Imprenta Nacional de Colombia. Bogotá D.C. 207 p.

CEPAL. (2016). CEPALSTAT, Bases de datos y Publicaciones estadísticas. En CEPALSTAT. Recuperado de http://interwp.cepal.org/cepalstat/WEB_CEPALSTAT/Portada.asp?idioma=e

Correa, E. P. (2012). América Latina: nueva ruralidad y exclusión social. Polígonos. Revista de Geografía, (15), 171-199. 
DANE. (2016). Conceptos básicos. En Departamento Administrativo Nacional de Estadísticas. Recuperado de https://www.dane.gov.co/files/inf_geo/4Ge_ConceptosBasicos.pdf

Fajardo Montaña, D. (2013). Colombia: dos décadas en los movimientos agrarios. Cahiers des Amériques latines, (71), 145-168.

FAJARDO, D. (2003). Propuesta para algunos contenidos del proyecto de la ley orgánica de Ordenamiento Territorial (LOOT) referidos en especial a asentamientos humanos y sector agrario. Red de Estudios de Espacios y Territorio. Espacio y Territorios. Razón pasión e imaginarios. Universidad Nacional de Colombia.

Fajardo, D. (2015). Estudio sobre los orígenes del conflicto social armado, razones de su persistencia y sus efectos más profundos en la sociedad colombiana. Conflicto social y rebelión armada en Colombia.

Harvey, D. (2006). Space as a Keyword. In Spaces of global capitalism, N.Y.

Hernández Fontecha, C. A. (2015). Concentración de la tierra en Colombia un obstáculo para el crecimiento: impacto sobre la producción agrícola de los departamentos-período 2000-2011.

Ibáñez Londoño, A. M. (2011). El desplazamiento forzoso en Colombia: un camino sin retorno hacia la pobreza. Cuadernos Geográficos, 48(1), 301-303.

Joumard, I., \& Londoño-Vélez, J. (2013). Income Inequality and Poverty in Colombia-Part 1. The Role of the Labour Market (No. 1036). OECD Publishing.

Ricardo, D. (2003). Principios de economía política y tributación. Ediciones Pirámide. 